\title{
Disruptive Space Technologies
}

\author{
Egbert Jan van der Veen, Institute of Space Systems, German Aerospace Center (DLR), \\ Bremen, Germany \\ Dimitrios A. Giannoulas, Institute of Space Systems, German Aerospace Center (DLR), \\ Bremen, Germany
}

Marco Guglielmi, European Space Research and Technology Centre, European Space Agency, Noordwijk, The Netherlands

Thijs Uunk, Delft University of Technology, Delft, The Netherlands

Daniel Schubert, Institute of Space Systems, German Aerospace Center (DLR), Bremen, Germany

\begin{abstract}
The theory of Disruptive Technologies explains the evolution of technologies that disturb the status quo of both dominant technology platforms and competitive market layouts. In this paper, the theory of Disruptive Technologies for the space sector is explored. This exploration is required because the Disruptive Technology theory is currently based upon the innovation dynamics of mass consumer markets, which are significantly different from the dynamics of the low volume, highly governmentally influenced space sector. The objective is to clarify the dynamics of innovation in space (with particular respect to technological disruptions) in order to help decision makers in their effort to support innovation in the development of space technologies. This is done by analyzing the dynamics of the space sector and the theory of Disruptive Technologies in respect to its applicability to the space sector. The result of these analyses leads to the creation of a theory that is tailored to the specific innovation dynamics of the space sector. The theory is termed Disruptive Space Technologies. Key element of this theory is the fact that Disruptive Technologies in the space sector focus mainly on technology disruption rather than market disruption.
\end{abstract}

Keywords: $\quad$ Diffusion of Innovations, Disruptive Innovation, Disruptive Space Technologies, Disruptive Space Technology, Disruptive Technology, Innovation Dynamics, Innovation Management, Space Innovation Management, Space Sciences

\section{INTRODUCTION}

The exploration (and exploitation) of space has resulted in many technological advances for humanity in areas such as materials, navigation, telecommunications, medicine and many

DOI: $10.4018 /$ ijstmi.2012070102 others. Improving the capabilities of space technologies, in order to increase the benefits that the utilization of space can offer, is a major goal of all space faring nations. Since the Apollo age, the space sector has concentrated mainly on a conservative method of technology development, focusing on low risk incremental innovations, rather than breakthrough, radical or disruptive innovations (Summerer, 2009). 
One of the reasons for this situation is the fact that space technology requires long and costly development phases with strict performance and environmental requirements. Another reason that can justify this situation is the very high cost of space transportation. These two factors have resulted in very stringent quality and flight heritage requirements. This situation, in turn, has created a paradigm, where the usage of technologies with meager or non-existing flight heritage is discouraged and, consequently, new technologies do not gain flight heritage because they are not selected (Szajnfarber, Grindle, \& Weigel, 2009). Despite the existence of several projects that are trying to bridge this valley of death within technology evolution, many technologies still end up in the dust bin after substantial investments. The valley of death is the gap of funding between basic technology development (push technology development up to Technology Readiness Level (TRL) 4/5) and application specific technology development (pull technology development after TRL 6/7). Because of the need to overcome the valley of death, there is a clear requirement for an early stage identification of technologies that could significantly improve the capabilities of space applications by disrupting the state-of-the-art. This early stage identification leads to the nurturing and protection of the right technologies against the valley of death and a resulting improvement of the capabilities of the space sector. This identification of potential highgain technologies can be achieved by mapping the factors that determine and influence the market potential of a technology. The most successful technologies will be disruptive to the state-of-the-art of space technologies and will therefore be called Disruptive Space Technologies (DSTs).

The aim of this paper is to create an understanding of the underlying processes that govern technology disruptions in the space sector. This understanding allows for an adaptation of the theory of Disruptive Technologies (DTs) to the unique market dynamics of the space sector. To gain this understanding, first the theory of DTs is subjected to a critical review. Different aspects of this theory are examined and evaluated with respect to their applicability to the unique market dynamics of the space sector. A new concept for evaluating technologies using a mix of performance attributes is also introduced here. Second, an analysis of the space sector is conducted. The factors that differentiate the space sector from conventional, terrestrial markets are discussed and the peculiarities of the space sector are explored. Third, the process of disruption in the space sector is investigated by analyzing a number of technologies that have been disruptive to the space sector in the past. The analysis of past DT's and their predecessors is done by using a mix of performance attributes for each technology, which is then evaluated by experts of the field. This leads to an insight into technology developments and disruptions in the space sector.

The research presented here was conducted at the German Aerospace Center in Bremen in cooperation with the European Space Agency (ESA) within the framework of a DLR project supported by ESA (Contract 4000101810/10/ NL/GLC).

\section{Theory of Disruptive Technologies}

Over the last few years the term Disruptive Technology (DT) has become a buzzword in several organizations around the world. The term, first explained by Bower and Christensen (1995), describes a technology that emerges out of a niche market and becomes so dominant that it disrupts the status quo of a market and often leads to incumbent companies being pushed out of the market. A new technology is classified disruptive when, in addition to serving a niche market, it starts to appeal to the majority of customers in the mainstream market. Christensen, Anthony, and Roth (2004) call this process "low-end disruption". This event occurs because the DT, through incremental technology improvements, starts to deliver the same (or better) performance than the previously dominant technology while also having additional attribute(s) that are valued by the niche market. When this happens, the new technology 
rapidly becomes the new standard and the old technology, and the companies that exploited it, are pushed out of the market.

A DT is an exemption to the incremental/ radical innovations paradigm, which Christensen (1997) classifies as sustaining innovations, because companies marketing these incremental/radical innovations continue to serve the same customers with the intention of sustaining their position in the market. The opposite of these sustaining innovations are DTs, which are technologies that disrupt the market of existing technologies exploited by incumbent companies. In practical terms this means that incumbent companies exploiting a dominant technology are being disrupted by new entrants exploiting a new technology (Carayannopoulos, 2009; Tellis, 2006).

Examples of incumbents disrupted by new entrants are illustrated in Table 1. Table 1 shows the dominant technology, the Disruptive Technology introduced by a new entrant, the disruptive attribute that constitutes the biggest source of change in the perceived customer value and therefore sparked the disruption and the period of disruption.

Companies marketing technologies attempt to satisfy customer demand. The demand or requirements for technology performance differ with every customer. In marketing literature this heterogeneity in customer demand is called customer-perceived value (Yang \& Peterson, 2004). In innovation management literature, this customer-perceived value has been used as a basis to segment markets according to the customer's assessment of the technologies performance dimensions. In this research, an attempt is made to determine the change in customer perceived value of a technology not on along a single performance attribute change (as addressed by the performance dimension by Christensen, 2007), or two attributes (as is popularized by the mapping of functional attributes by Adner, 2002) but rather on a mix of performance attributes (e.g. cost, mass, effectiveness, efficiency).

For this purpose, a concept under the term perceived performance mix is hereby introduced by the authors. It represents a mixture of the relevant performance attributes as perceived valuable by a customer or a part of the market. This leads to the following definition:

The perceived performance mix is the mix of functional attributes of a technology as appeared valuable to the customer.

The alternate performance mix of a DT can fulfill a performance mix that is perceived as valuable by customers of the main market or by customers of a niche market. This can either be a push development (where a product is created to fulfill a performance mix not previously addressed) or a pull development (where a product is developed to meet the demand for a certain performance mix). Regardless whether the new product is developed from a push or a pull perspective, it starts disrupting an incumbents' market. A further illustration of the concept of perceived performance is given by means of the example of portable music players:

\section{Table 1. Examples of DTs}

\begin{tabular}{|l|l|l|l|}
\hline \multicolumn{1}{|c|}{$\begin{array}{c}\text { Dominant Technology } \\
\text { (Incumbent) }\end{array}$} & $\begin{array}{c}\text { Disruptive Technology (New } \\
\text { Entrant) }\end{array}$ & \multicolumn{1}{|c|}{ Disruptive Attribute } & \multicolumn{1}{c|}{$\begin{array}{c}\text { Period of } \\
\text { Disruption }\end{array}$} \\
\hline Workstation & Personal computer & Affordability & 1980's \\
\hline 5.25 inch disk drive & 3.5 inch disk drive & Size, weight (laptops) & 1980 's \\
\hline Compact Cassette & Compact Disc & Sound quality, capacity & 1990 's \\
\hline Chemical photography & Digital photography & Capacity, development cost & 2000's \\
\hline Discman & Mp3 player & Portability, capacity & 2000's \\
\hline
\end{tabular}


The music industry has been a platform for several disruptions over the last decades. Changing sound recording formats, due to advancements in technology, have led to the development of a variety of portable music players to support each format. With the introduction of portable mp3 players to the market in the late 1990s, the Discman (portable CD-player) market has undergone a significant disruption (Beaudry, 2007). This disruption was primarily owed to the change of how the customers valued certain performance attributes. Figure 1 illustrates this change with the help of a radar chart. The image shows the performance attribute mix as it was before and after the introduction of $\mathrm{mp} 3$ players. Sound quality used to be valued most by the customers since this was the main advantage that the CD had over the cassette. Additionally, battery life and exchangeability of medium were very important. With the introduction of the mp3 format, however, this changed dramatically. Sound quality had reached a level where improvements would not have led to noticeable differences and battery life had become sufficient for extensive use. The result was that customers started focusing more on other attributes like capacity, exchange of music over the internet and portability. This ultimately led to a disruption of both the Discman as the dominant portable music player platform and well as a failure of the next generation sustainable innovation of the Minidisc player.

This shift in the value of products as perceived by customers is a gradual process over time, is influenced by external factors. Examples of external factors would be a reach of basic functionality or functional threshold after which customers become ambiguous to any further improvements. This saturation of customer demand leads to a refocusing of technical performance to secondary performance measures such as aesthetics, functionality and cost. This change in perceived value of a product is essential for understanding of this concept and for Disruptive Technologies in general, as it is often the alternate performance mix that appeals to the customers and thus making the technology disruptive and not one single performance attribute. This can be very well seen in the example of the Discman: despite the fact that the sound quality of the $\mathrm{CD}$ is vastly superior to the mp3 (Meyer, 2000), Discmans reached a point of sound quality that was satisfying enough for the mainstream customers. People consequently stopped valuing the performance mix of the $\mathrm{CD}$ and turned to the performance mix provided by the mp3 format, although inferior on some attributes. Because of the DT's

Figure 1. Change in perceived performance mix of portable music players. A higher score means a better performance on this attribute. Data comes from authors'experience and serves for illustration purposes only.

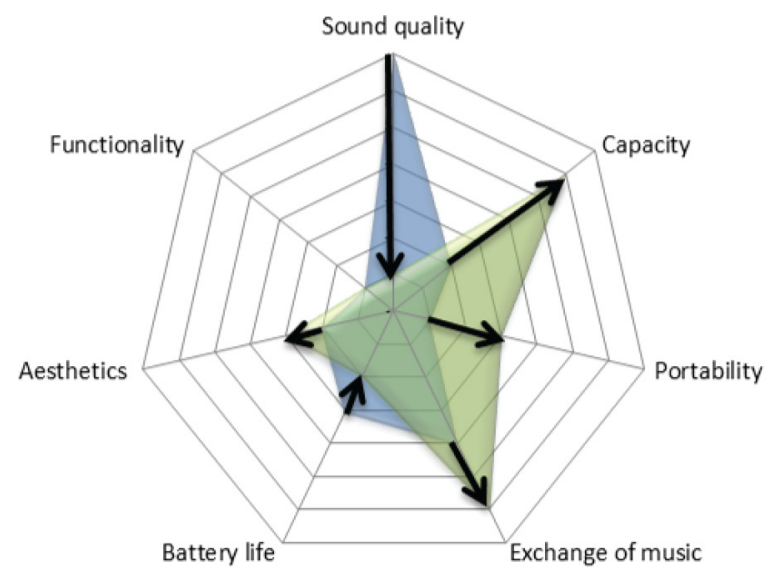

Before 2000

After 2000

Copyright (C) 2012, IGI Global. Copying or distributing in print or electronic forms without written permission of IGI Global is prohibited. 
initial inferiority and differences in the perceived performance mix, incumbent companies are often blindsided and cannot see its potential. They believe that the new technology can only serve a niche market and that the majority of their customers will not value its use. In fact, it is often the customers themselves that tell the incumbents that they do not value the new features (Christensen, 1997). In conclusion, the latent customer needs of technologies are often the main source of disruptions.

The theory of technology displacements stems from the original concept of creative destruction by Schumpeter (1942). Over the years the concept evolved and different terms were added to the theory such as Technology Discontinuation \& S-Curves (Foster, 1986), Radical, Incremental,Architectural \& Modular Innovation (Henderson \& Clark, 1990), Disruptive Technologies (Bower \& Christensen, 1995), Disruptive Innovation (Christensen \& Raynor, 2003). A more elaborate history of the evolution of the theory of technology displacements can be found in Figure 2 (Yu $\&$ Hang, 2010). In recent years, the usage of the term Disruptive Technology has become highly ambiguous. Christensen himself added to the ambiguity of the term by proposing to rename DTs into Disruptive Innovations (DIs) (Christensen \& Raynor, 2003). Christensen proposed this alteration to the theory because a market disruption has been found to be not a function of technology itself but rather of its changing application. By taking the example of the portable music players, it can be argued that not the MP3 player technology but rather the market enabled the technology to become disruptive. This alteration broadens the theory to encompass all innovations and not just technologies, which are defined as practical applications of scientific knowledge (products). This means that the theory encompasses now also disruptive innovations, thus including process, paradigm and position innovations. Markides (2006) states that broadening the concept is a mistake because different kinds of innovations have different competitive effects and produce different kinds of markets. The authors tend to agree to this point and are therefore continuing to use the term DTs especially since this article

Figure 2. Evolution of disruptive technology/innovation theory with the addition of the space sector

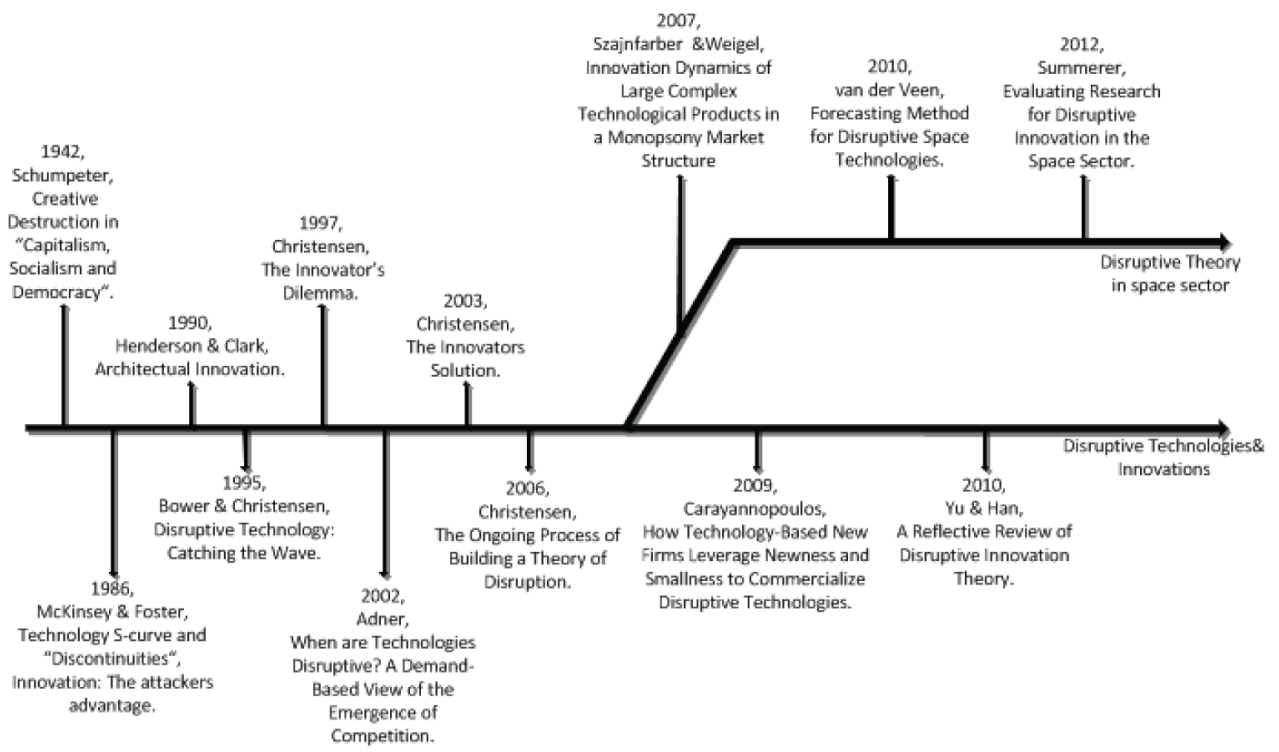

Copyright $(\underset{2}{2012}$, IGI Global. Copying or distributing in print or electronic forms without written permission of IGI Global is prohibited. 
focusses solely on the disruption of technologies (products of the space sector). Like Markides, other researchers have also raised questions regarding the theory of DTs. Some of these questions are listed below:

- Is a technology inherently disruptive or does disruptiveness depends on the perspective of the firms confronted with the technical change? (Schmidt \& Druehl, 2008)

- How can the theory be used as a predictive tool? (Tellis, 2006)

- What is the exact definition of a DT? (Danneels, 2004)

- The theory names the creation of spin-offs as a solution to deal with DTs. What and when should this be done? (Danneels, 2004)

- When is a DT disrupting a dominant technology? (Danneels, 2004)

- Can the theory be used for creating instead of identifying DTs? (Yu \& Hang, 2010)

These gaps in the theory have become known to the researchers working in this field and many have made attempts to fill them. Some examples are listed below:

- Paap and Katz (2004) utilize the theory of S-Curves as a method to model the underlying factors influencing disruptive innovations;

- Govindarajan and Kopalle (2005) propose a method to measure the disruptiveness of innovations;

- Christensen (2006) explains a method that can be used to recognize the next disruptive innovations on the horizon;

- Drew (2006) uses scenario planning methods to identify disruptive innovations at an early stage;

- Adner(2006) proposes a method to identify how the customers perceived performance changes as a technology evolves. This method is used as an indicator for new disruptive threats;
- Sainio and Puumalainen (2007) have devised a method to measure the disruptive potential of a new technology;

- Sood and Tellis (2011) have created a model for understanding and predicting DTs;

- Chan Kim and Mauborgne (2005) have created a method for identifying new-market disruptions.

Most researchers are focusing on the predictability of DTs as this would be the most beneficial to companies dealing with a potential disruption. However, thus far no consensus has been reached as to what a DT precisely is and as a logical effect, how it can be predicted. In fact, no evidence of any method that can accurately identify or predict the course that a disruptive technology takes has been found to date. It seems that the theory is suffering from the fact that the spectrum of situations classified as disruptive is too broad as well as the fact that creating a unified theory capable of describing disruption in a range of markets with different market dynamics has proven difficult.

Because of this, researchers have begun to adapt the general theory of disruption to several specialized fields. The following fields have adopted a customized view of how DTs diffuse according to their unique market dynamics:

- Education(Christensen, Horn, \& Johnson, 2008);

- Medicine (Christensen, Grossman, \& Hwang, 2009);

- $\quad$ Military (Mitchell, 2009);

- $\quad$ Gaming technology (Smith, 2007);

- Information technology (Peterson, Anderson, Culler, \& Roscoe, 2003);

- $\quad$ Space(Summerer, 2009; Summerer, 2012; Veen, 2010).

To summarize the theory of DTs, several articles are used that provide a description of the theory. The main characteristics of a DT, according to Adner (2002), Gilbert (2003), 
Tripsas (2008) and Govindarajan and Kopalle (2005) are:

- DTs initially serve a different market segment than the dominant technology. Possible market segments are:

- A niche market (part of the market with different requirements);

- A low-end market (part of the market where customers have a lower willingness to pay);

- A high-end market (part of the market where customers have a higher willingness to pay);

- A fringe market (a market that is similar to the main market).

- At the moment of entrance into the market, DTs have a worse performance compared to the dominant technology in the main performance attribute(s). This leads to an under-appreciation by the incumbents of the technology, which effectively facilitates its entry into the market. When the DT starts maturing, however, it surpasses the dominant technology in terms of performance by better fulfilling the customer needs. This happens because of its alternate mix of performance attributes.

From the aforementioned insights, the following working definition of a DT is derived:

A disruptive technology is a technology that alters the status quo of both the market position of the dominant technology and the competitive market layout by having an alternative perceived performance mix, which is valued more by the customer than the one of the dominant technology.

\section{Space Sector Innovation}

In the previous section, the general theory on DTs has been presented. In order to understand the mechanisms of market disruption in the space sector, as opposed to other technology sectors, an analysis of the space sector is examined by exploring specifics and peculiarities.

The space sector is a high-technology sector, which is instrumental in advancing a range of scientific fields (e.g. meteorology, astronomy, earth science, geodesy telemedicine). Due to research and development efforts and the resulting innovations, the technological capabilities of the space sector are steadily increasing. In practice, however, innovation in space is more frequently incremental upon the dominant technology and provides small improvements in the performance of a technology. According to Summerer (2009) this is partially caused by a risk-averse culture in the space sector, leaving little room for the testing of innovations in subsystems that are not imperative for achieving mission success.

According to Tkatchova (2011), research and development and the diffusion of innovations within the space sector are different when compared to terrestrial consumer markets. Space is an especially harsh environment, which is not only hard to reach but also hard for technologies to operate in. This creates unique constraints in the form of additional operational requirements that greatly exceed those required for terrestrial technologies. These operational requirements are determined by the following environmental constraints:

- High-energy radiation;

- Extreme temperatures;

- Large and frequent temperature variations;

- Micrometeoroid and orbital debris impacts;

- Vacuum environment;

- High g-forces during launch;

- Microgravity environment; 
- $\quad$ Limited opportunities for repairs or adjustments after launch.

The constraints of the space environment have led to strict quality requirements for space technologies, since the failure of even a single component could potentially lead to a mission failure. In order to maintain a high degree of component reliability, the following measures are taken:

- $\quad$ Strict testing requirements;

- Proven space flight heritage requirements;

- High need for redundancy or diversity;

- Strict quality assurance and quality control processes.

An additional issue that is specifically relevant to space is the low volume demand for space technologies as compared to mass markets. This, combined with high launch costs and tight import/export and health regulations (e.g. International Traffic in Arms Regulations (ITAR), Registration, Evaluation, Authorizations of Chemicals (REACH)), make the space sector an especially hard environment for start-ups.

Furthermore, an additional specific aspect of the space sector is that it is governed by market dynamics that are different from those of the mass consumer market. The market dynamics of the space sector are influenced by the actors and their interaction. In general, two types of customer-seller relationships exist with respect to technology development: the consumer and the governmental demand driven markets. In the first, the consumers' needs are central and translate to specific technology requirements. In the second, governmental needs, which can be either militarily or scientifically driven, are central. This difference in customer-seller interaction means that the innovation dynamics in the scientific and military fields differ from those in the commercial field. In general, the following market forms can be identified:
- Mass market - Many sellers that face many buyers;

- Monopoly market - One seller that faces multiple buyers;

- Monopsony market - One buyer that faces multiple sellers;

- Oligopoly market - Few sellers that face multiple buyers;

- Oligopsony market - Few buyers that face multiple sellers.

The space sector in respect to science missions has been characterized as a monopsony market in which the government is the main investor in space related technologies (Szajnfarber \& Weigel, 2007; Summerer, 2012). It can be argues that the military has similar dynamics while to commercial market resemble more an Oligopolistic market structure.

Finally, there is one more difference between the space market and the general mass market. In the mass market, the product (or technology) is usually operated directly by the end user. For space technology, this is not necessarily true since, in general, most space technologies (for example functional telecommunications satellites) are operated by satellite operators who, in turn, sell their services to end users or service providers (Public Customers (PC) or Institutional Customers (IC) in Figure 3).

In the scenario of telecommunications satellites, the service providers are the real customers of the space technology (STC in Figure 3) and the space technology utilization is separated from the space technology development. The result of this separation is one of the reasons for the barriers for adoption of new space technologies and the resulting slow evolution of the space sectors' capabilities.

Furthermore, it must be noted that space technology customers (especially within the telecommunication market) are generally not very motivated to bear the risk of testing and trying out a new technologies without an external incentive since that results in higher costs thus lower profit margins. A much preferred 
Figure 3. Key players in the space technology market

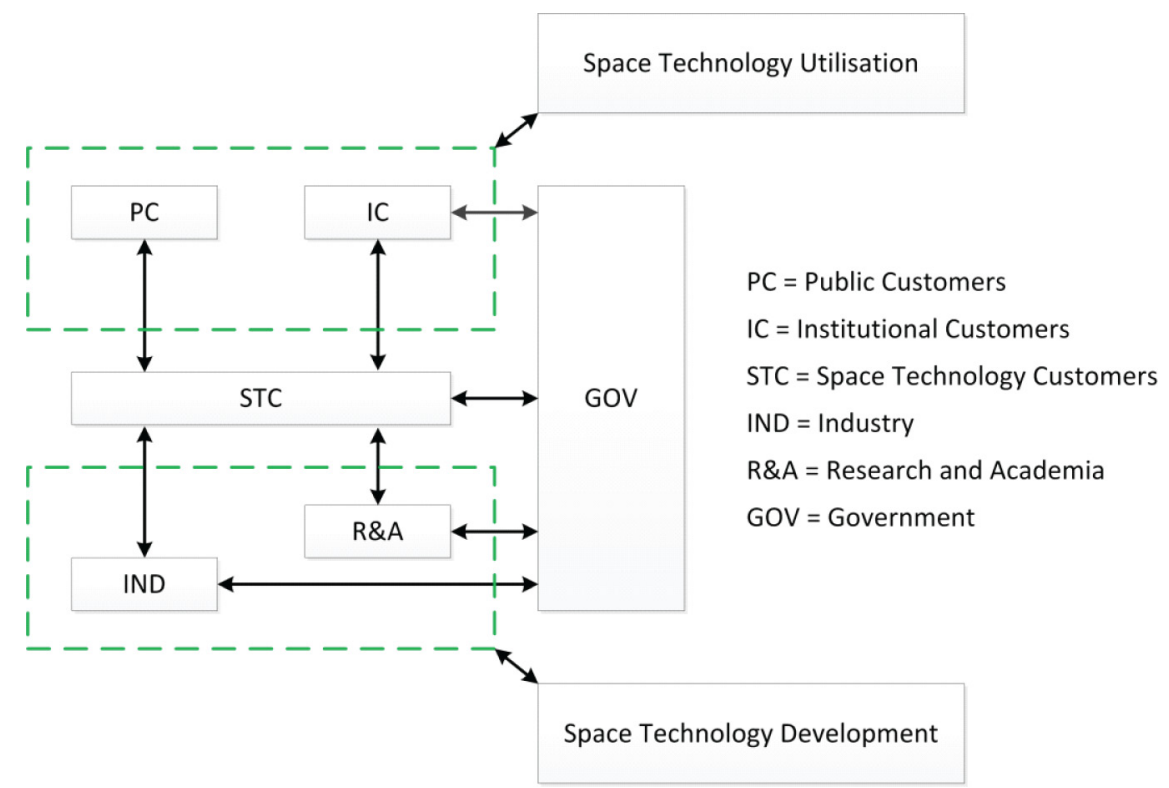

approach is to configure the space segment in a way that changes in performance can be delivered to the PC and the IC without the need of changes in the space hardware. This is particularly evident in the telecommunications sector where satellites can be seen, which were built more than 10 years ago, that are broadcasting the highly advanced signals of High Definition television (HDTV), although HDTV did not even exist when the satellites were developed (this has amongst others, been enabled by turbo coding).

At this point, it has been established that the space sector market structure and resulting innovation dynamics is significantly different from other high-technology sectors. This leads to a technology development process that is also different from other high technology sectors. These characteristics of technology development within the space sector are elaborated next.

In the space sector, a distinction can be made between basic technology development and mission specific technology development. When looking through the so called technology push and demand pull models, basic technology developments can be identified as the technology push factor, mission specific technology developments can be identified as the demand pull factor (Summerer, 2012). Especially technology push investments result in breakthrough technologies whereas demand pull investments result in more incremental innovations (Nemet, 2009; Carayannis \& Roy, 2000). This is primarily because technology push investments involve more fundamental research and application of novel materials whereas demand pull investments involve the improvement of existing technologies or designs. Taking this into account, the technology push area of technology development may appear to be the most interesting when it comes to introducing DTs in the space sector. Therefore, in order to cultivate DTs in the space sector, it seems that technology push investments have to be increased. However, there are two main reasons why technology push investments in the space sector are impeded.

The first reason is that mature technologies are favored in the selection processes for technology development programs. This is because 
the lion's share of technology development in the space sector is undertaken in the frame of a mission development program (demand pull investments). Peculiarly, this creates an impending dead-lock of technological development, since a certain technology is only developed if it is considered to be mature enough for a mission. This problem is amplified by the fact missions are proposed only if the scientist involved consider them as technologically feasible. In other words, large gaps between technological stateof-the-art and technological mission demands are avoided (Szajnfarber, Grindle, \& Weigel, 2009). This can be a hindrance to innovation as only sufficiently ambitious technological demands really drive innovation (Szajnfarber, Stringfellow, \& Weigel, 2010).

The second reason is that technologies need to be tested and eventually flight-proven. Flight-proving a technology is often the largest hurdle to take in any space technology development program. This is a direct result of the risk-averse nature of the space sector, which prevents non-conservative and innovative technologies to be tested and flight-proven on commercial telecommunications and navigation missions. In fact, not being able to properly test and subsequently flight-prove a technology is the main reason why a significant amount of technologies never reach full maturity.

The situation is, however, very different in the context of Science and Earth Observation missions. The customers of this part of the space sector are usually scientists, which have an ever increasing demand for new types of advanced space sensors. This need allows them to drive mission requirement to a point where using innovative less proven technologies can become an absolute imperative. This is in contrast to telecommunication satellite operators for whom the investment into new, risky technology does not prove to be economically viable. Because of this, Science and Earth Observation missions can be seen as the lead users for the space sector providing flight heritage to space technologies which can later be used for commercial satellites. Some examples of past DSTs which have been matured specifically for Science and Earth Observation missions at the European Space Agency are listed below:

- Goce: Drag compensation technology (Fehringer, Andre, Lamarre, \& Maeusli, 2008);

- Smos: Interferometric radiometry (Drinkwater, Kerr, Font, \& Berger, 2008);

- Hershel: Silicon Carbide mirrors (Crone, Elfving, Passvogel, Pillbratt, \& Tauber, 2006);

- Gaia: Silicon Carbide structure (Douglas, et al., 2007; Gare, Sarri, \& Schmidt, 2009).

Particularly interesting is the case of Silicon Carbide manufacturing that was first developed for a mirror application for Hershel, and was subsequently infused in Gaia, but for a different application.

To further illustrate relevant aspects of technology development, and to get a better idea of how technology development in the space sector works, it is useful to analyze the diffusion of innovation within the space sector. A popular method of visualizing technology development within a certain technology sector is the hype cycle (Fenn \& Raskino, 2008). This method, originally developed by Gartner, can be used to map the various upcoming and mature technologies in any technology sector or domain (Fenn \& Raskino, 2008). As an example, a hype cycle with the various technologies within the propulsion and power domains of the space sector is displayed in Figure 4. Note that the graph does not display the technological maturity, but rather the perception of the potential (expectation) for the technology.

In conclusion, it has been established that the space sector market structure and the resulting technology development process differs 
Figure 4. Hype cycle of the space sector. Data comes from authors' experience and serves for illustration purposes only.

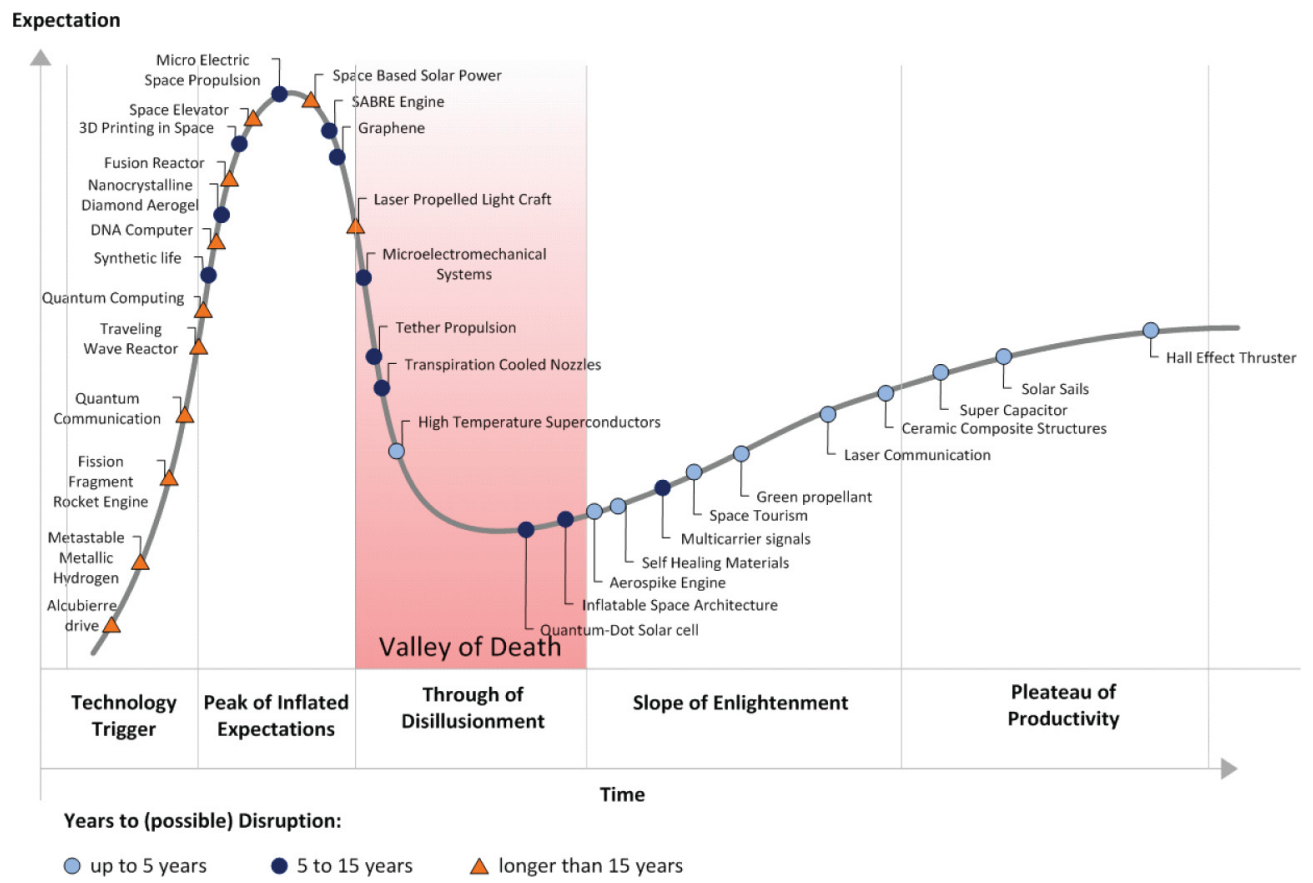

significantly from other high-technology sectors. This means that the characteristics of technology disruption have to be revised for the space sector in order to take into account these differences.

\section{Theory of Disruptive Space Technologies}

In the previous sections, the theory of DTs and the market dynamics of the space sector have been discussed. It was concluded that the space sector is sufficiently different from terrestrial consumer markets that a reassessment of the theory of DTs is required for the space sector. To better understand the impact, evolution and manifestation of DSTs and the path they take in replacing existing technologies, several technologies that have been disruptive to the space sector in the past have been analyzed. The analysis of these technologies shows that space technologies are highly subject to the perception of performance of a customer as it is the case with non-space technologies. The detailed analysis and the data used are too lengthy and exceed the scope of this paper and thus, only the results are presented here. Several examples of past disruptions are illustrated in Figure 5 with the help of radar charts. The example of miniature satellites is chosen to illustrate lowend encroachment within the space sector. These types of satellites are overall inferior in technical performance compared to regular satellites and it is solely the unique mix of performance attributes that these types of satellites offer (combination of functionality with low cost \& low complexity) that appears valuable to certain customers. However, as determined in the section above, the customer-seller relationship within the space sector is significantly differ- 
Figure 5. Performance mixes of DST (blue) vs. former dominant technology (green)

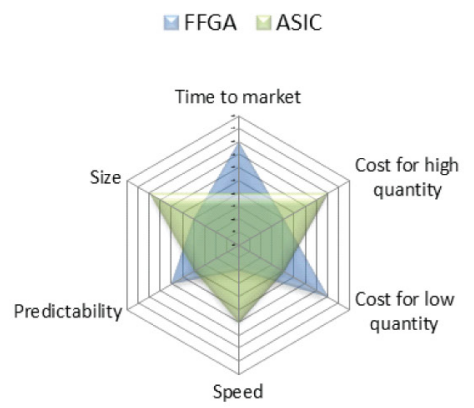

$\square$ Miniature Satellites $\square$ Conventional Satellites
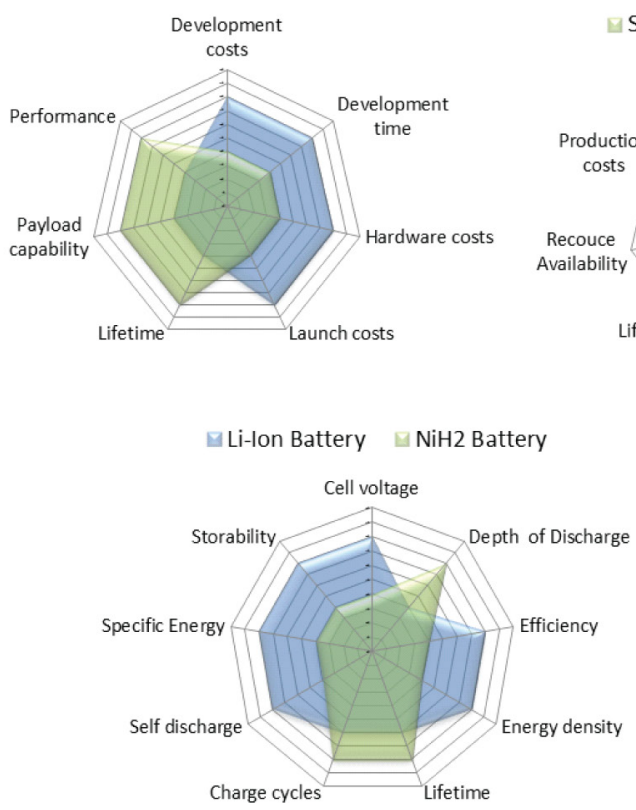

$\square$ Ka-Band $\square$ C-Band

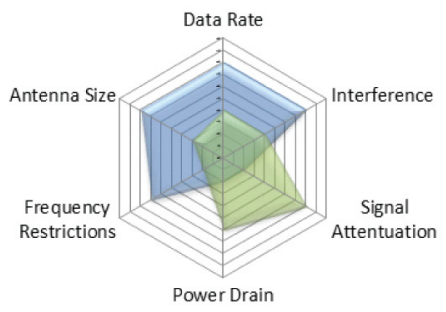

Triple junction solar cells

Silicon solar cells

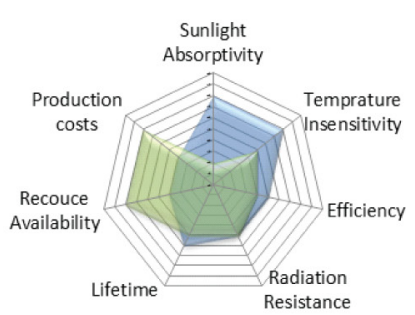

ent compared to the mass consumer market. Because of an increased customer power and the comparative small size of the space sector, following the disruption no major shifts were observable in the competitive market layout. This coincides with the standpoint on DT presented in Schmidt \& Dreuhl (2008). According to this standpoint, the theory of DTs should relax the constraint that DTs have to be introduced by new entrants and focus less on the competitive market layout disruption and more on pure technology disruption. This standpoint has merit especially for the space sector where basic technology development is mostly the product of institutes and research groups.

The past DSTs share the common characteristic of having a different mix of performance attributes compared to the dominant technolo- 
gies. This allowed them to first enter a niche market (for instance a specific scientific mission) before encroaching on the market of a dominant technology. Because of this, the scientific missions could be seen as the lead users of the space sector. While the over-performance on a mix of performance attributes is a characteristic DSTs share with DTs, the following differences between the two can be observed:

- Development time: The development of a space technology takes a long time and, therefore, the response time of the incumbents to DSTs is high. They have the opportunity to either start a development process of their own (if the development time permits it) or take over the company marketing the new technology. Either way, the incumbents are unlikely to be pushed out of the market by a DST;

- Flight heritage: A dominant space technology already has a long flight heritage. A new space technology candidate must deliver a very significant improvement on the dominant technology to justify the increase in risk and cost when using the new space technology;

- Market characteristics: the space sector is a complex market that is highly influenced by governmental entities. Development and usage of a technology is often linked to political motives, national industrial policy, and other social aspects.

When analyzing innovation literature and the theory of DTs, a resemblance can be found between radical innovations and DSTs. Both are explorations of new technologies and replace dominant technologies. Additionally, they both offer a higher performance on the perceived performance mix compared to the dominant technology. The key difference between these theories is that DSTs do this in an unexpected way or, in other words, by over performing on an alternative performance mix, which is valued by customers of a niche market. This means that the disruption of technologies is mostly governed by market factors rather than technical performance superiority. It is the market

Figure 6. Aggregation level pyramid with respect to radical innovation within the space sector. SoS $=$ System of Systems

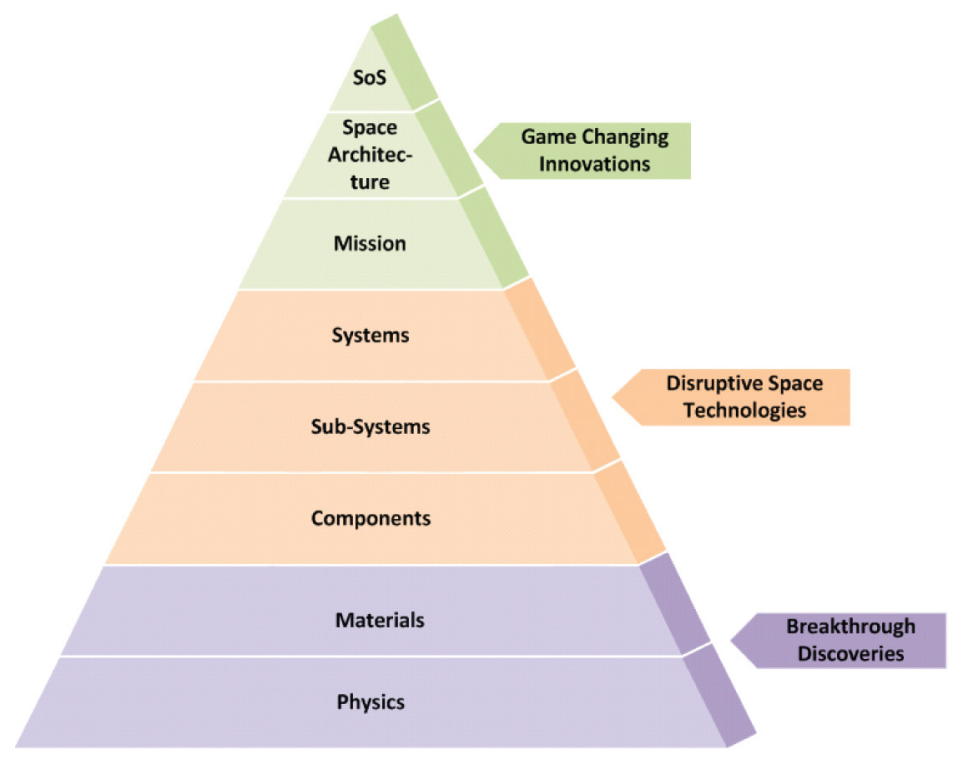

Copyright $(\odot$ 2012, IGI Global. Copying or distributing in print or electronic forms without written permission of IGI Global is prohibited. 
that changes in an unexpected way and thereby facilitates the disruption of the state-of-the-art technology by a DST. The insights mentioned above lead to the following definition of a DST:

A Disruptive Space Technology is a technology that radically changes the status quo of the space sector by having an alternative perceived performance mix, which fulfills the user's technology requirements better than the dominant technology.

It is important to note that also many ambiguous terms have been used to classify disruptive, discontinuous or radical innovations within the space sector. For example, within the European space sector, the term Disruptive Technologies is predominant while in the US the term Game Changing Technology is prevalent. Additionally, the term Breakthrough Discoveries seems to be the leading term for basic technologies such as materials and fundamental physics. Because of this, it would be useful to have a structure of classification that fits the existing terminologies as close as possible. Such a structure of classification of technology replacement is proposed in Figure 6.

\section{CONCLUSION}

Since its conception, the space sector has relied heavily on governmental contributions for funding of technology developments. In this respect, the space sector is somewhat of a late bloomer seeing as other historical high tech industries such as the railroad industry, the terrestrial telecommunications industry, the aircraft industry and computer industry all required an initial government investment before it was feasible for commercialization to occur. The space sector has not gone through this commercialization process yet, but it is possible, if more is invested in the development of technologies with a high disruptive potential. This would lead to a future where lower cost and higher performance increases the utilization of space for commercial ventures such as earth observation, telecommunication $\&$ navigation while possibly opening it up to new ventures such as space tourism, space based solar power and asteroid mining. This paper intends to contribute to the process of space innovation by helping decision makers with the identification of future DSTs.

\section{REFERENCES}

Adner, R. (2002). When are technologies disruptive? A demand-based view of the emergence of competition. Strategic Management Journal, 23(8), 667-688. doi:10.1002/smj.246

Adner, R. (2006). Match your innovation strategy to your innovation ecosystem. Harvard Business Review, 84(4), 98-107.

Beaudry, D. N. (2007). The effects of technology convergence on markets. In Proceedings of the Dynamics of Globalization-AIB US-Northeast Chapter Meeting, Portsmouth, NH.

Bower, J.L., \& Christensen, C. M. (1995). Disruptive technologies: Catching the wave. Harvard Business Review, 43-53.

Carayannis, E. G., \& Roy, R. I. (2000). Davids vs Goliaths in the small satellite industry: The role of technological innovation dynamics in firm competitiveness. Technovation, 20(6),287-297. doi:10.1016/ S0166-4972(99)00137-6

Carayannopoulos, S. (2009). How technologybased new firms leverage newness and smallness to commercialize disruptive technologies. Entrepreneurship Theory and Practice, 33(2), 419-438. doi:10.1111/j.1540-6520.2009.00297.x

Christensen, C. M. (1997). The innovator 's dilemma: When new technologies cause great firms to fail. Boston, MA: Harvard Business School Press.

Christensen, C. M. (2006). The ongoing process of building a theory of disruption. Journal of Product Innovation Management, 23(1),39-55. doi:10.1111/ j.1540-5885.2005.00180.x

Christensen, C. M., Anthony, S. D., \& Roth, E. A. (2004). Seeing what's next. Boston, MA: Harvard Business School Publishing. 
Christensen, C. M., Grossman, J. H., \& Hwang, J. (2009). The innovator's prescription: A disruptive solution for health care. New York, NY: McGrawHill Professional.

Christensen, C. M., Horn, M. B., \& Johnson, C. W. (2008). Disrupting class: How disruptive innovation will change the way the world learns. New York, NY: McGraw-Hill Professional.

Christensen, C. M., \& Raynor, M. E. (2003). The innovator's solution: Creating and sustaining successful growth. Boston, MA: Harvard Business School Press.

Crone, G., Elfving, A., Passvogel, T., Pillbratt, G., \& Tauber, J. (2006). Unveiling the universe. ESA Bulletin, 128, 10-17.

Danneels, E. (2004). Disruptive technology reconsidered: A critique and research agenda. Journal of Product Innovation Management, 21, 246-258. doi:10.1111/j.0737-6782.2004.00076.x

Douglas, J., de Bruijne, J., O’Flaherty, K., Prusti, T., O’Mullane, W., \& Lammers, U. (2007). Pinpointing the Milky Way - The formidable challenge of processing Gaia's data. ESA Bulletin, 132, 26-33.

Drew, S. A. (2006). Building technology foresight: Using scenarios to embrace innovation. European Journal of Innovation Management, 9(3), 241-257. doi:10.1108/14601060610678121

Drinkwater, M., Kerr, Y., Font, J., \& Berger, M. (2008). Exploring the water cylce of the blue planet. ESA Bulletin, 137, 7-24.

Fehringer, M., Andre, G., Lamarre, D., \& Maeusli, D. (2008). A jewel in ESA's Crown. ESA Bulletin, $133,14-24$.

Fenn, J., \& Raskino, M. (2008). Mastering the hype cycle: How to choose the right innovation at the right time. Boston, MA: Harvard Business Press.

Foster, N. R. (1986). Innovation: The attacker's advantage. Mandaluyong City, Malaysia: Summit Books.

Gare, P., Sarri, G., \& Schmidt, R. (2009). ESA's billion pixel camera. ESA Bulletin, 137, 51-59.

Gilbert, C. (2003). The disruption opportunity. MIT Sloan Management Review, 44(4), 27-32.

Govindarajan, V., \& Kopalle, P. K. (2005). The usefulness of measuring disruptiveness of innovations ex post in making ex ante predictions. Journal of Product Innovation Management, 23(1), 12-18. doi:10.1111/j.1540-5885.2005.00176.x
Henderson, R. M., \& Clark, K. B. (1990). Architectural innovation: The reconfiguration of existing product technologies and the failure of established firms. Administrative Science Quarterly, 35, 9-30. doi:10.2307/2393549

Markides, C. (2006). In need of better theory. Journal of Product Innovation Management, 23(1), 19-25. doi:10.1111/j.1540-5885.2005.00177.x

Meyer, C. (2000). Doppelt blind, MP3 gegen CD: Der Hörtest. c't, 2000(3), 144.

Mitchell, S. T. (2009). Identifying disruptive technologies facing the United States in the next 20 years. Fort Leavenworth, KS: U.S. Army Command and General Staff College.

Nemet, G. F. (2009). Demand-pull, technology-push, and government-led incentives for non-incremental technical change. Research Policy, 38(5), 700-709. doi:10.1016/j.respol.2009.01.004

Paap, J., \& Katz, R. (2004). Anticipating disruptive innovation. Research-Technology Management, 47(5), 13-22.

Peterson, L., Anderson, T., Culler, D., \& Roscoe, T. (2003). A blueprint for introducing disruptive technology into the Internet. In Proceedings of the First Workshop on Hot Topics in Networks, Princeton, NJ: Computer Communication Review.

Sainio, L.-M., \& Puumalainen, K. (2007). Evaluating technology disruptiveness in a strategic corporate context: A case study. Technological Forecasting and Social Change, 74(8), 1315-1333. doi:10.1016/j. techfore.2006.12.004

Schmidt, G. M., \& Druehl, C. T. (2008). When is a disruptive innovation disruptive? Journal of Product Innovation Management, 25, 347-369. doi:10.1111/j.1540-5885.2008.00306.x

Schumpeter, J. A. (1942). The process of creative destruction. In Schumpeter, J. A. (Ed.), Capitalism, socialism and democracy (pp. 81-87). New York, NY: Harper.

Smith, R. (2007). The disruptive potential of game technologies: Lessons learned from its impact on the military simulation industry. Research Technology Management, 50(2), 57-64.

Sood,A., \& Tellis, G. J. (2011). Demystifying disruption: A new model for understanding and predicting disruptive technologies. Journal of Marketing, 30(2), 339-354. 
Summerer, L. (2009). Specifics of innovation mechanisms in the space sector. In Proceedings of the XXth ISPIM Conference - The Future of Innovation, Vienna, Austria.

Summerer, L. (2012). Evaluating research for disruptive innovation in the space sector. Acta Astronautica, 81, 484-498. doi:10.1016/j.actaastro.2012.08.009

Szajnfarber, Z., Grindle, A. T., \& Weigel, A. L. (2009). Instantiations of government space innovation systems: A comparitive analysis. In Proceedings of the International Astronautical Congress (IAC) 2009, Daejeong, South Korea.

Szajnfarber, Z., Stringfellow, M. V., \& Weigel, A. L. (2010). The impact of customer-contractor interactions on spacecraft innovation: Insights from communication satellite history. Acta Astronautica, 67(9-10), 1306-1317. doi:10.1016/j.actaastro.2010.07.003

Szajnfarber, Z., \& Weigel, A. L. (2007). Innovation dynamics of large complex technological products in a monopsony market structure: The case of ESA science missions. In Proceedings of the Atlanta Conference on Science Technology and Innovation Policy Atlanta, GA, (pp. 19-20). Ieee.
Tellis, G. J. (2006). Disruptive technology or visionary leadership? Journal of Product Innovation Management, 23(1), 34-38. doi:10.1111/j.15405885.2005.00179.x

Tkatchova, S. (2011). Space-based technologies and commercialized development. Hershey, PA: IGI Global. doi:10.4018/978-1-60960-105-8

Tripsas, M. (2008). Customer preference discontinuities: A trigger for radical technological change. Managerial and Decision Economics, 29(2-3), 79-97. doi:10.1002/mde.1389

Veen, E. J. (2010). Forecasting method for disruptive space technologies. In Proceedings of the Toulouse Space Show 2010, Toulouse, France.

Yang, Z., \& Peterson, R. T. (2004). Customer perceived value, satisfaction, and loyalty: The role of switching costs. Psychology and Marketing, 21(10), 799-822. doi:10.1002/mar.20030

Yu, D., \& Hang, C. (2010). A reflective review of disruptive innovation theory. International Journal of Management Reviews, 12(4), 435-452. doi:10.1111/j.1468-2370.2009.00272.x 